\title{
EVOLUÇÃO NO ATENDIMENTO AOS CLIENTES DA USINA DE MONLEVADE: BREVE E RECENTE HISTÓRICO*
}

\author{
Eduardo de Oliveira Diniz ${ }^{1}$ \\ Gustavo Lambert Boratto ${ }^{2}$ \\ llemar Geraldo de Vasconcelos Júnior ${ }^{3}$ \\ José Pantuza Torres ${ }^{4}$ \\ Marília Lopes da Costa ${ }^{5}$ \\ André de Souza Almeida ${ }^{6}$ \\ Christiane Pereira Simões ${ }^{7}$ \\ Jairo Alves Pereira ${ }^{8}$ \\ Wellington Carlos Ventura ${ }^{9}$
}

\section{Resumo}

"Excelência no atendimento aos clientes" é uma máxima declarada como busca constante em todos os segmentos de mercado, inclusive no de aços longos, negócio da ArcelorMittal Monlevade. Com foco neste objetivo, muitas vezes, a empresa se volta para o mercado na tentativa de mapear as necessidades dos clientes. Após identificá-las, e absorvê-las, acaba-se criando complexidades em processos tanto em produtos quanto em serviços. A cada internalização de demanda, segue-se a rotina sob a ameaça de transformar o processo de atendimento em algo confuso e desatualizado, além de não haver segurança de que o cliente está satisfeito de fato. Este trabalho mostra o histórico recente de uma expressiva evolução do atendimento aos clientes da unidade de Monlevade, resultado obtido através de análises, utilizando a metodologia PDCA, que orientaram a uma nova estrutura da equipe de atendimento na Gerência de Logística, implicando em reformulação de acompanhamentos/controles de processos e intensificação dos contatos com pessoas envolvidas com atendimento aos clientes dentro e fora da planta. Com isso, foi possível superar, de forma consonante, a proposta da Logística Central de implantação de uma "Célula de Atendimento" em cada unidade da ArcelorMittal. Conclui-se que é necessário rever periodicamente a rotina de processos internos de modo a buscar um equilíbrio entre as necessidades dos clientes, complexidades geradas e resultado dos índices de atendimento.

Palavras-chave: Atendimento; Controle de processo; ArcelorMittal Monlevade.

\section{DEVELOPMENTS IN CUSTOMER SERVICE OF MONLEVADE PLANT: BRIEF AND RECENT HISTORY}

\section{Abstract}

"Excellence in customer service" is a must declared, as a constant search at all market segments including the Long Carbon Steel, business segment of ArcelorMittal Monlevade. With this goal, many times, the company is back to the market in an attempt to map and identify today's customer needs. After identifying and understanding them, they end up creating complexity in our internal processes, with the risk of transforming the process of customer service in a confusing environment, and there is no security that the customer is, in fact, satisfied. This work details the recent improvement at customer service of the Monlevade Plant, result obtained through analysis using the PDCA method, which guided to a new structure of the customer service team at the Logistics Management Department, implying a reengineering of follow ups/process controls and intensification of contacts with people involved with customer service inside and outside the plant. In this way, it was possible to overcome, aligned with the proposal of ArcelorMittal Brazil Central Logistics the deployment of a "Serving Cell" in each unit of ArcelorMittal. We conclude that it is necessary to review periodically the routine of internal processes in order to seek balance between customers' needs, complexities and results of customer service indicators.

Keywords: Customer service; Process control; ArcelorMittal Monlevade.

\footnotetext{
Engenheiro Metalurgista, Gerente de Logística, João Monlevade, MG, Brasil. Administrador, Gerente de Área de Logística, João Monlevade, MG, Brasil.

Administrador, Analista Pleno de Planejamento e Logística, João Monlevade, MG, Brasil.

Administrador, Coordenador Técnico PPCP, João Monlevade, MG, Brasil.

Técnico em Metalurgia e Informática, Técnico Programação Logística Atendimento à Exportação, João Monlevade, MG, Brasil.

Técnica em Metalurgia e Gestão de Negócios, João Monlevade, MG, Brasil.

Técnica Programação Logística Atendimento a Coligadas, João Monlevade, MG, Brasil.

Tecnólogo em Logística, Técnico Programação Logística Atendimento a Transferências, João Monlevade, MG, Brasil.

Administrador, Auxiliar técnico Atendimento clientes Aços ATC e Mercado Interno, João Monlevade, MG, Brasil.
} 


\section{INTRODUÇÃO}

De um lado uma questão fundamental, sistêmica e, portanto complexa, para o negócio da ArcelorMittal Monlevade: o atendimento aos clientes. De outro, o rigor da certeza científica nos impele a procurar novas maneiras de controlar e mensurar o atendimento na visão ampla da Logística. Diante deste contraste, há que se considerar o quão difícil é ser assertivo na interpretação dos resultados quando se tem uma Usina integrada, que trabalha make to order, e onde uma interferência pontual em qualquer estágio do processo pode causar grandes prejuízos no atendimento aos clientes.

Com grande volume de produção, poucos fornecedores e muitos consumidores, a indústria siderúrgica ainda é um oligopólio no mundo - especialmente com as fusões e aquisições da última década. Este setor ainda se caracteriza por reduzida diferenciação de produtos, ofertas de preços e condições de pagamento muito parecidas. Por esses motivos o diferencial competitivo deve estar na qualidade do produto e em elevados níveis de atendimento em serviço.

Serviços englobam pré-venda, venda e pós-venda. Ao cliente interessa o conjunto dessas fases. Porém, cada cliente tem sua forma de medir o nível de serviço de acordo com sua conveniência, que pode estar mais concentrada em seu fluxo de caixa, na capacidade de estocagem, lead-time, serviços urgentes, resposta às reclamações, assistência técnica, etc.

A Kotler é atribuída a criação do conceito de "Produto ampliado", o qual afirma que o cliente não compra o produto em si, mas também sua parte intangível, isto é, o conjunto de serviços/benefícios que o acompanha [3]. Cabe bem aplicá-lo ao fio-máquina, uma vez que, em se tratando de produtos com pouca diferenciação entre concorrentes, o que vai angariar a preferência do cliente não será só a qualidade e integridade do produto, mas o pacote de serviços que o acompanha.

Este trabalho objetiva e se limita a tratar o nível de atendimento da ArcelorMittal Monlevade medido pelo indicador OTIF (On Time, In Full - ou seja, o pedido atendido no tempo combinado, em seu volume completo, na qualidade especificada). Portanto, 0 OTIF pode ser considerado um indicador de satisfação global.

O OTIF é um indicador aceito universalmente e considerado um KPI - Key Performance Indicator (indicador de desempenho de processo chave) - enquanto outros precisam de ajustes para sua aplicação, como é o caso, por exemplo, do SLA (Service Level Agreement - acordo de nível de serviço), que é um "pacote de serviços" negociado com o cliente e registrado em contrato. Este último prevê penalidades em caso de não cumprimento e bônus em caso de over performance. Neste caso, pode-se lembrar de Bowersox [1], que ponderava que praticamente qualquer nível de serviço logístico pode ser realizado desde que a empresa esteja disposta a assumir os custos (trade-off).

\section{MATERIAL E MÉTODOS}

Dentre as diversas variáveis que envolvem o processo de atendimento em Monlevade, podemos destacar como determinantes observadas para este estudo:

a) Externas: situação do mercado, orientações de estratégias corporativas de vendas e/ou de produção, ciclo de registro de pedidos, interferências na carteira confirmada, oferta de transporte e performance das transportadoras, urgências que implicam em alteração de modal de expedição, fluxo de compra e recebimento de tarugos de terceiros, condições de estocagem nos depósitos avançados, demandas específicas e reclamações de cada cliente.

b) Internas: rupturas inerentes ao processo da cadeia produtiva (exemplos: quebra de equipamento, conflitos interdepartamentais na rotina), complexidade da produção bitola $x$ aço, produto sem especificação de qualidade exigida, qualidade do estoque 
intermediário, criticidade do pedido, restrição do espaço físico para estocagem, falha de sistema, baixa automatização dos processos logísticos, falha operacional, alta rotatividade e qualificação da mão-de-obra.

Para trabalhar um projeto com esta vasta quantidade de variáveis que interferem no atendimento, utilizou-se o MASP - Método de Análise e Solução de Problemas, também chamado QC Story. Este é um método bastante abrangente, que deriva do ciclo PDCA. O MASP se aplica justamente em casos de problemas sistêmicos e crônicos e se caracteriza pela objetividade do estudo de fatos e dados em etapas, conforme apresentado na figura abaixo.

O que se busca com este método é suscitar análises que visam reduzir as incertezas ao longo da cadeia, com foco em atingir o índice mínimo de $92 \%$ na avaliação mensal de OTIF até dezembro de 2014 e, consequentemente, elevar o nível de satisfação dos clientes e contribuir para manutenção do market share da ArcelorMittal Monlevade.

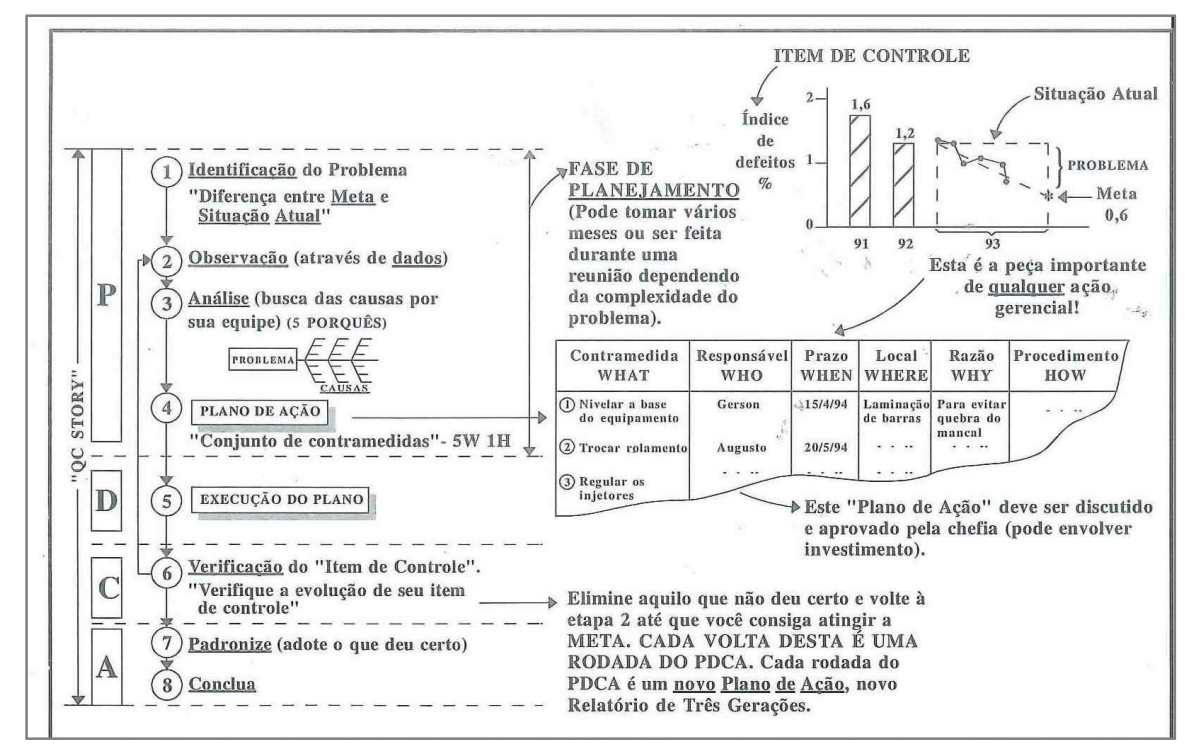

Figura 1.Como atuar gerencialmente utilizando o PDCA [2].

\section{RESULTADOS}

Os mais importantes resultados alcançados estão apresentados a seguir:

- Elevação apreciável no patamar do índice do atendimento OTIF (índice apurado e divulgado pela Corporação na segunda quinzena de cada mês).

Referência: Atendimento Volume \& Item, comparando data de entrega no cliente $x$ data de remessa confirmada dos pedidos.

- Redução no índice de reclamações dos clientes por Serviços. Em 2014, 90\% do volume reclamado até agosto foi por atraso na entrega pelas transportadoras.

Referência: Comparativo entre tonelagem reclamada (reclamações procedentes) $x$ tonelagem faturada no período.

- Finalmente, uma melhoria na gestão da qualidade do estoque de tarugos. Este item é ao mesmo tempo uma causa e uma consequência da melhoria do atendimento aos clientes.

Referência: Vide Gráfico 3. 


\section{$34^{\circ}$ Logística}

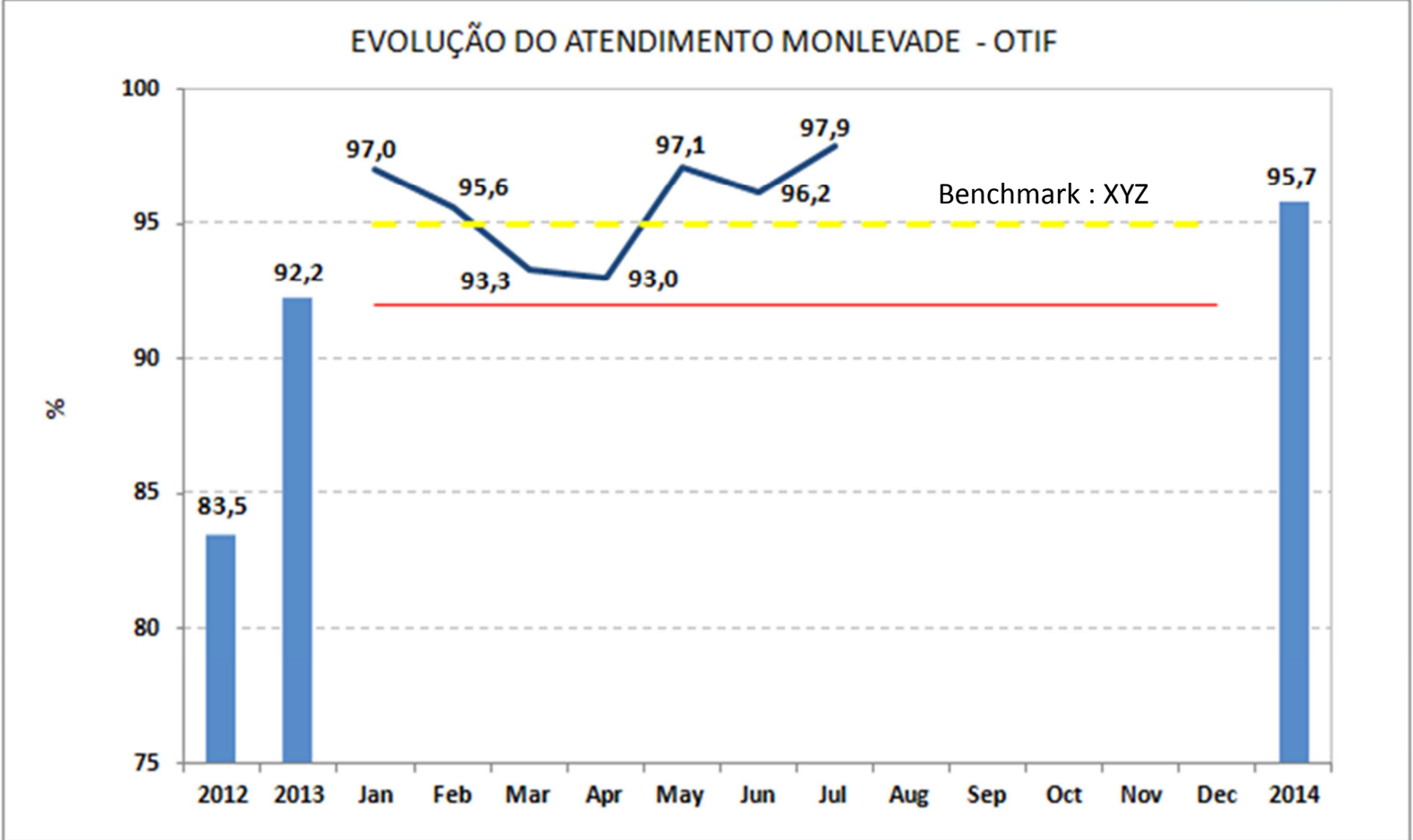

Gráfico 1. Evolução do atendimento OTIF em Monlevade. Fonte: Dados primários (2014)

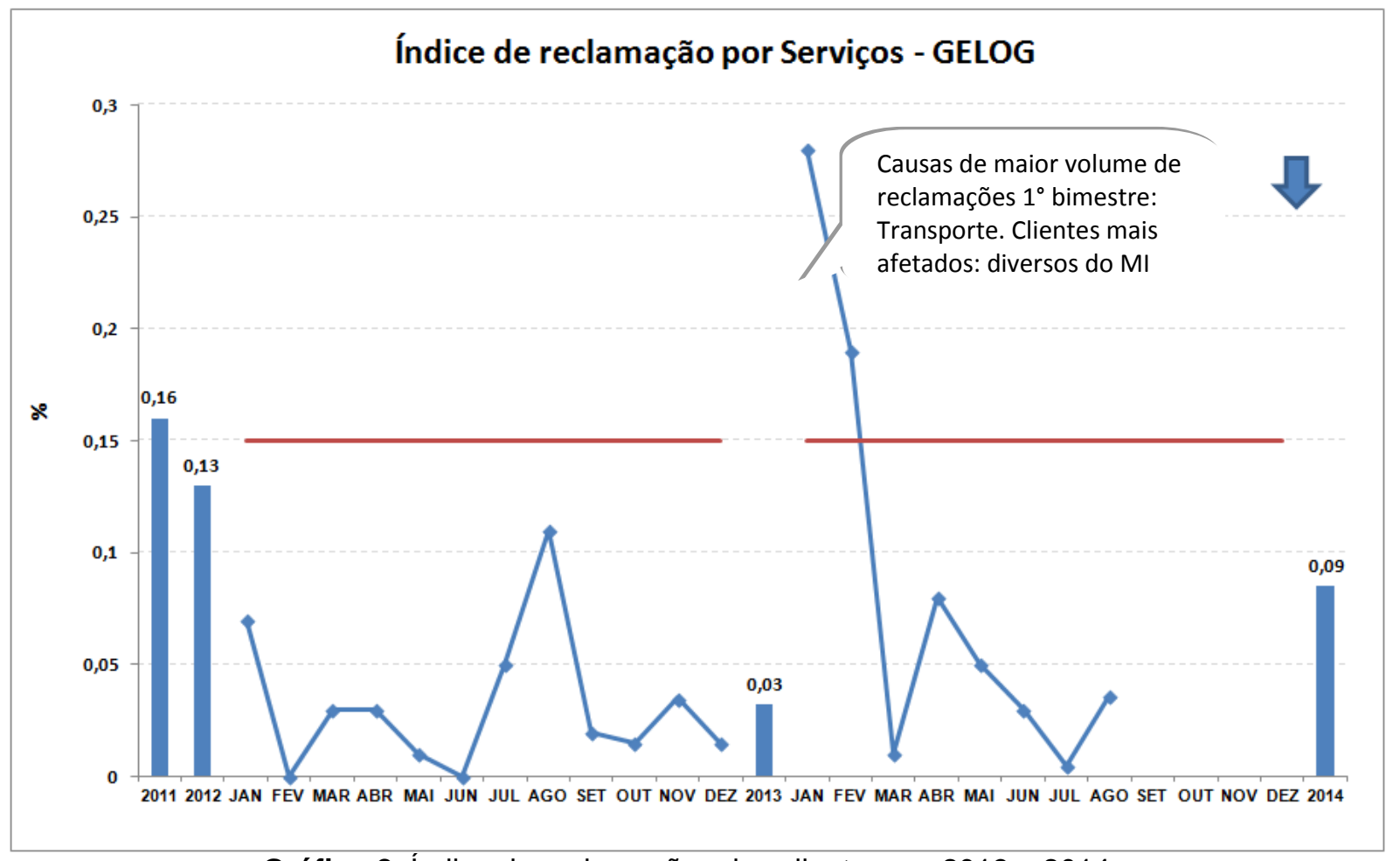

Gráfico 2. Índice de reclamações dos clientes em 2013 e 2014.

Fonte: Dados primários (2014) 


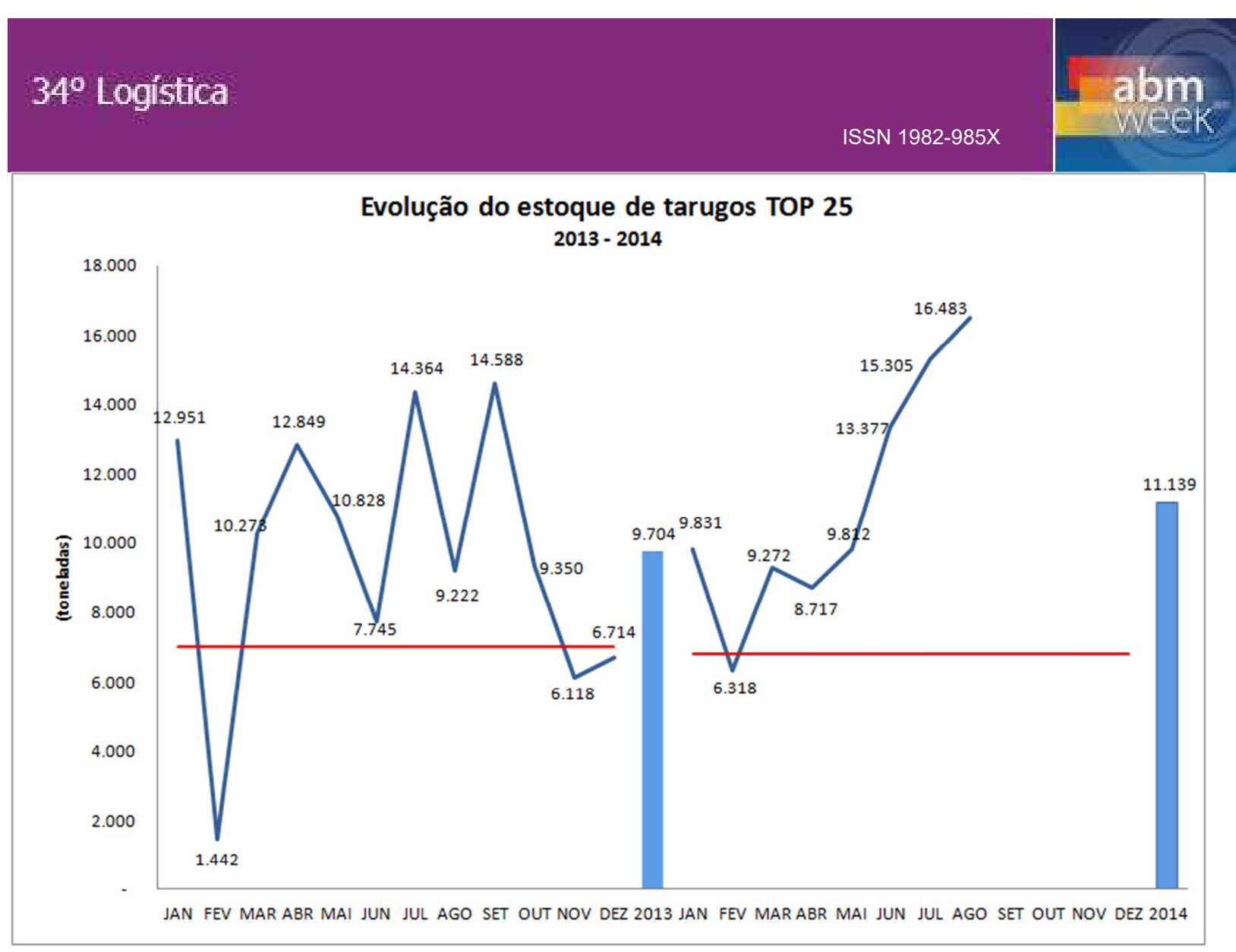

Gráfico 3. Evolução do estoque de tarugos TOP 25.

Fonte: Dados primários (2014)

\section{DISCUSSÃO}

Há uma particularidade na Usina de Monlevade que torna sua administração diferente das demais unidades do Grupo ArcelorMittal Brasil: ser uma Usina de aços longos make to order. Logo, o processo de atendimento também é afetado por esta característica.

Atualmente, a Célula de Atendimento desta Usina está especialmente atenta aos seguintes pontos, que podem causar descontinuidade operacional - por segmento de mercado:

- Empresas Coligadas (Belgo Bekaert Arames): Frequência das interferências na carteira, VMI (Vendor Management Inventory) Belgo Bekaert Arames, controle de expedição e faturamento por terminal (atualmente, VL! e Tora Logística) e solicitação de entrega por rodovia.

- Aços ATC e Clientes do Mercado Interno: VMI XYZ (portal Elemica), entregas programadas para clientes do mercado interno e do Aços ATC, seleção de embarque de corridas por envelhecimento no estoque (cliente XYZ) e por \% Ceq (Belgo Bekaert Arames).

- Exportação: Acompanhamento do volume de embalagem, saída de cargueiros e programação urgente de altos volumes por rodovia, devido a atrasos em Monlevade ou antecipação do layday dos navios.

- Transferências para outras unidades do grupo: Frequência das interferências na carteira, solicitação de entrega por rodovia.

- ArcelorMittal Sabará, concentração da carteira no TL2, na segunda quinzena do mês e alto volume de aços para molas e hastes de amortecedores (aproximadamente $50 \%$ até agosto de 2014).

- Distribuição e Transporte: Controle de atendimento ferroviário da Vale (manobras, entrega de vagões, montagem de cargueiros, movimentação de tarugos externos), tempo de permanência e de carregamento dos veículos dentro da planta, custos de frete, transportadora versus destino, expedição por modal. 
Todos os controles são feitos manualmente, com base em relatórios do SAP (ECC, SCM, BW), MES e SCV, e compilação de informações recebidas dos clientes por e-mail, em gráficos e planilhas do Excel, pois não há recursos de TI desenvolvidos para todos esses controles. Para melhoria desta etapa do processo há projetos de automatização em andamento.

Essa última questão fato nos coloca em um cenário altamente operacional, o que dificulta o ambiente analítico. Vale ressaltar que o ambiente BW do SAP, que fornece dados de forma mais estruturada, no formato de grandes tabelas dinâmicas, fica mais restrito ao planejamento da produção, controle de carteira e custos de frete. Além disso, não há carga de dados on-line.

\section{CONCLUSÃO}

A resposta da escolha e aplicação da metodologia MASP se mostrou positiva para a evolução do índice OTIF.

A equipe da Gerência de Logística, em especial, da Célula de Atendimento vem se adaptando aos novos relatórios e controles sugeridos, a despeito dos limites na automação dos mesmos. Por outro lado, observa-se real intensificação dos contatos entre as pessoas envolvidas com atendimento aos clientes dentro e fora da Usina. Notase ainda investidas em descomplicar o trabalho quando são feitos questionamentos mais frequentes do tipo: "este relatório ainda é útil? Esses dados estão gerando informações que me levam a decisões corretas? Esta é a melhor forma de fazer o trabalho"?

Alguns estudiosos sugerem que se deve medir o nível de atendimento pela resposta do próprio cliente. De fato, este retorno é importantíssimo, entretanto não se pode contar unicamente com esta informação. É preciso ter atenção em momento de negociações de preços, assédio do concorrente ou de fornecimento aberto, isto é, aquele em a empresa não é fornecedora exclusiva. A transparência da resposta pode estar estrategicamente afetada quando em oportunidades de negócio. Estas são boas razões para insistir no MASP: apuração de fatos e dados.

Historicamente, na indústria em geral, nota-se que é preciso haver sinergia entre equipes de Marketing, Vendas e Logística para estudar o comportamento do cliente, dada a complexidade de sua mensuração, que esbarra em teorias de psicologia social, em estudo de cenários econômicos e suas tendências, valores individuais das empresas compradoras, volume de dinheiro envolvido nas transações versus saúde financeira das empresas compradoras, entre vários outros fatores.

Finalmente, pode-se perceber o momento de estabilidade operacional que a ArcelorMittal Monlevade vem experimentando ao longo deste ano. Não resta dúvida que este fator, aliado a uma postura gerencial voltada para o atendimento ao programa de produção nas várias fases do processo produtivo, é crucial para garantir o bom nível de atendimento aos clientes.

\section{REFERÊNCIAS}

1 Bowersox, D. Logistical Management. New York, Macmillan Publishing, 1978.

2 Campos, Vicente F. Gerenciamento da rotina de trabalho do dia-a-dia. Rio de Janeiro: Bloch Editores, 1994.

3 Kotler, P; Armstrong, G. Princípios de Marketing. São Paulo, Phb: 2003. 